\title{
Evaluation of SRE Scenarios for Penang, Selangor and Johor in Peninsular Malaysia using PRECIS Regional Climate Model (RCM)
}

\author{
Kah Seng Chin ${ }^{1}$ and Kok Weng Tan ${ }^{1 *}$ \\ ${ }^{1}$ Faculty of Engineering and Green Technology, Universiti Tunku Abdul Rahman, Jalan Universiti, \\ Bandar Barat, 31900 Kampar, Perak, Malaysia
}

\begin{abstract}
Climate change is unambiguous as there is much evidence from around the world showing that changes have already occurred. This phenomenon is in response to an array of human activities, notably the release of greenhouse gases; an understanding of the rate, mode and scale of this change is now of literally vital importance to society. Researchers utilize climate models to study the dynamics of our changing climate and also to make future projections. Climate models are basic representation of many interactions within the Earth's climate which includes the atmosphere, land surface, oceans and ice. These models are typically quantitative in nature and range from simple depictions of the climate to very complex ones. In this present study, downscaled PRECIS regional climate models (RCMs) were used to project the average minimum and average maximum temperatures and average precipitation for Penang, Selangor and Johor in Peninsular Malaysia. The RCM projections for these three states were developed based on ECHAM4 A2 and ECHAM5 A1B scenarios for the years 1980 to 2069 and ECHAM4 B2 scenario for the years 2010 to 2069 . Bias correction will be applied to the simulated historical data to remove common systematic model errors. Historical observation data of monthly average minimum and maximum temperatures and monthly average rainfall from the Malaysian Meteorological Department (MMD) will be used in the bias correction. Finally, a RCM scenario which matches with the historical observation data of the three states for future projections will be recommended.
\end{abstract}

\section{Introduction}

Earth surface temperature records have clearly indicated that the climate of the earth is warming. The Intergovernmental Panel on Climate Change (IPCC) Fourth Assessment Report (AR4) has come with a $0.74{ }^{\circ} \mathrm{C}$ increase in global average surface temperature for the past 100 years based upon past IPCC assessments and new findings reported in various researches. This unprecedented increase is primarily due to increasing concentration of aerosols and greenhouse gases (GHG) in the atmosphere and the main drivers of this increase are either from natural or man-made emissions. The AR4 also showed that extreme

\footnotetext{
${ }^{*}$ Corresponding author: tankokweng@,utar.edu.my
} 
rainfall events have surged over most land areas, consistent with global warming and increase of atmospheric water vapor [1].

Global climate models (GCMs) are developed by assumptions on the evolution of drivers of climate change to study the earth's climate system in the past and future. GCMs are utilised to project the changes in atmospheric variables under the climate change scenarios defined by the IPCC. Climate projections from GCMs are defined at a coarse grid (approximately 150-300 km). However, this poor spatial resolution is often biased and hence cannot be used to conduct local climate change impact studies [2]. In order to bridge the gap between the coarse scales of simulated climate and the local scales with important features such as clouds and topography, a whole new discipline has been sprouted that is usually referred to as "downscaling" [3].

The term "downscaling" represents the method by which local-to regional-scale (10$100 \mathrm{~km}$ ) climate information is derived from coarse resolution (more than $100 \mathrm{~km}$ ) atmospheric data or GCM output. There are two main downscaling techniques; dynamic downscaling and statistical downscaling. In dynamic downscaling, a regional climate model (RCM), which closely resembles the atmospheric GCM, is formed for a region of interest located within a GCM [4]. It uses time-varying atmospheric boundary conditions around a specified domain modelled by a GCM. As compared to GCM, RCM has a higher resolution (approximately $12-50 \mathrm{~km}$ ) and it preserves the physical coherence between atmospheric and land surface heterogeneities [5-6]. However, RCMs maintain the biases and other deficiencies of the GCM, and therefore statistical downscaling is often needed also for RCM projections. The basic rule in statistical downscaling is to define a relationship between the large-scale atmospheric model (either GCM or RCM) and the local climate. Statistical downscaling methods are computationally inexpensive as compared to dynamic downscaling and can be applied to the output from GCMs or RCMs [7]. The basic assumption applied is that the relationship between large and local scale will remain constant in the future. Since this basic assumption cannot be verified, it became the major limitation in statistical downscaling [2]. 


\section{Background of the study area}

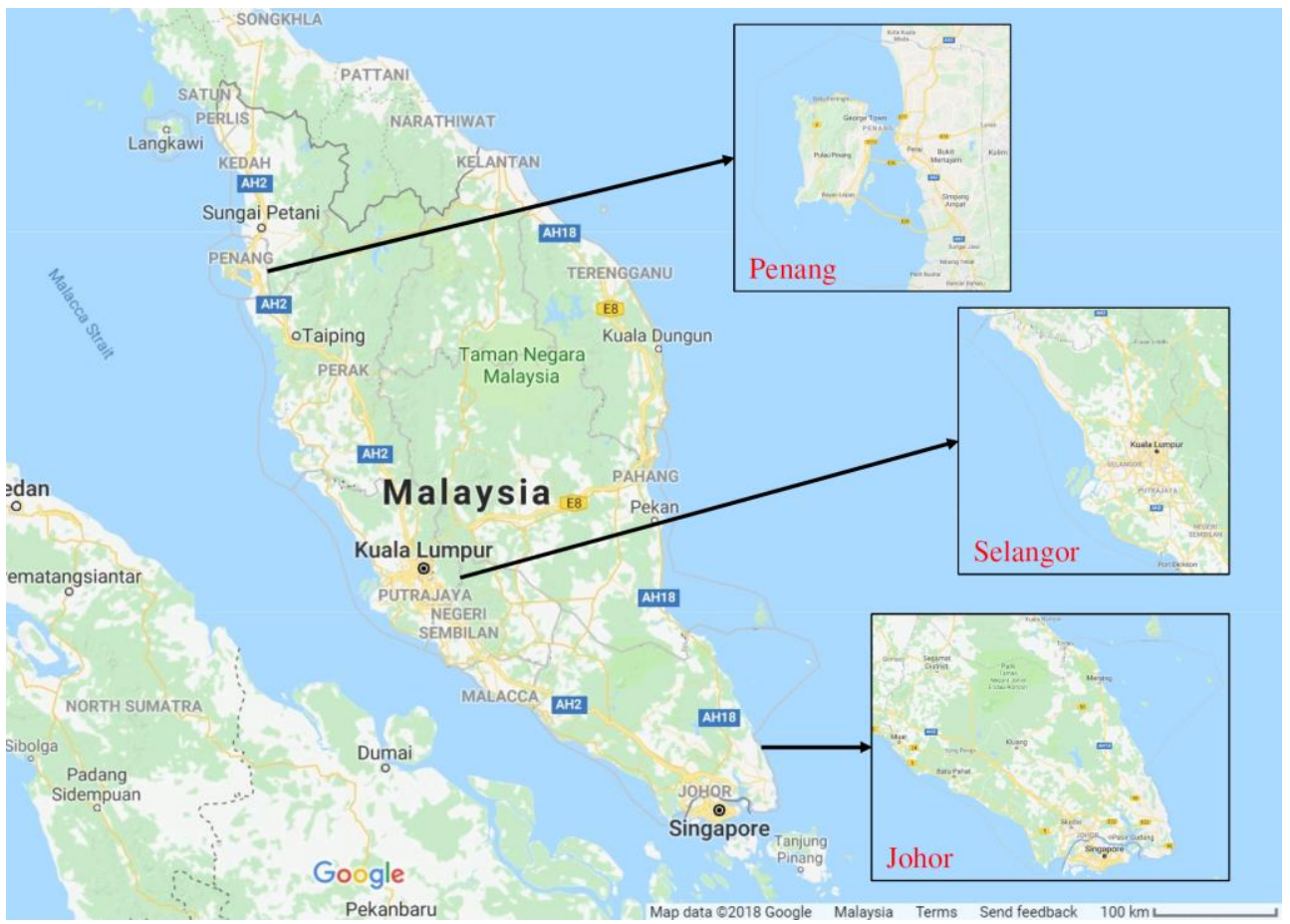

Fig. 1. Location of the study sites (Source: Google Maps, 2018)

Peninsular Malaysia is situated at the western part of the Maritime Continent, as shown in Fig. 1. The surface climate and weather fluctuation over the Maritime Continent is modulated mainly by the Asian-Australian monsoon. This large-scale circulation in this region is extensively studied by numerous researchers [8-17].

Penang, Selangor and Johor, as shown in the subsets of Fig. 1, are selected in this study because these three states have the highest industrial activities in Peninsular Malaysia, based on the gross domestic product (GDP) statistics and they have the highest pace of urban development experienced thus can show significant effects of climate change in Peninsular Malaysia [18]. Penang and Selangor are situated on the west coast of Peninsular Malaysia while Johor is located at the bottom tip of Peninsular Malaysia. Penang $\left(5^{\circ} 25^{\prime} \mathrm{N} 100^{\circ} 20^{\prime} \mathrm{E}\right)$ has a total area of $1,048 \mathrm{~km}^{2}$, situated to the north west of Perak and bordered by Kedah to the north and the east, is the second smallest state in Malaysia by land mass. Selangor $\left(3^{\circ} 20^{\prime} \mathrm{N} 101^{\circ} 30^{\prime} \mathrm{E}\right)$ and Johor $\left(1^{\circ} 29^{\prime} \mathrm{N} 103^{\circ} 47^{\prime} \mathrm{E}\right)$ have a total area of $8,104 \mathrm{~km}^{2}$ and $19,102 \mathrm{~km}^{2}$, respectively. Selangor is bordered by Perak to the north, Negeri Sembilan to the south, Pahang to the east and the Straits of Malacca to the west. Johor is bordered by Pahang to the north, Negeri Sembilan and Malacca to the northwest and the Straits of Johor to the south.

\section{Downscaled regional climate model analysis and SRE scenarios}

The RCMs applied in this present study belonged to the fourth and fifth-generation of atmospheric general circulation models (GCMs), i.e. ECHAM4 \& ECHAM5, developed at 
the Max Planck Institute for Meteorology [19-20]. These RCM data were obtained from Southeast Asia START (System for Analysis, Research and Training) Regional Centre, Chulalongkorn University, Thailand. The regional climate scenarios were projected at high resolution of .22 degree (approximately $25 \mathrm{~km} \times 25 \mathrm{~km}$ ) and rescaled to resolution of $20 \mathrm{~km}$ $\times 20 \mathrm{~km}$ based on dynamic downscaling process using PRECIS (Providing Regional Climate for Impacts Studies) which is a regional climate modelling system developed by the Hadley Centre for Climate Prediction and Research [21].

The IPCC has defined 40 scenarios classified into 4 core families' marker scenarios. Each family are given an abbreviation (A1, A2, B1 and B2) to reflect a particular evolution of humankind which have different rates of GHG emissions into the atmosphere in regard to economic activity, population growth, technology distribution and others. Global and regional climate models capture the climate response to these different scenarios [22].

The A1 scenario defines a future world of very rapid economic growth, global population that peaks in mid-century and declines thereafter, and the rapid introduction of new and more efficient technologies. Major underlying themes are convergence among regions, capacity building, and increased cultural and social interactions, with a substantial reduction in regional differences in per capita income. The A1 scenario family expands into three groups that describe alternative directions of technological change in the energy system. The three A1 groups are distinguished by their technological emphasis: fossil intensive (A1FI), non-fossil energy sources (A1T), or a balance across all sources (A1B). One of the projections discussed in this study is based on scenario A1B which simulated a future where economic growth is sustained and technology is shared between developed and developing countries in order to reduce regional economic disparities [23].

The A2 scenario describes a very heterogeneous world. The fundamental theme is selfreliance and preservation of local identities. Fertility patterns across regions converge very slowly, which results in continuously increasing global population. Economic development is primarily regionally oriented and per capita economic growth and technological change are more fragmented and slower than in other scenarios [23].

The B2 scenario outlines a world in which the emphasis is on local solutions to economic, social, and environmental sustainability. It is a world with intermediate levels of economic development, continuously increasing global population at a rate lower than A2, and less rapid and more diverse technological change than in the A1 and B1 scenarios. While the scenario is also focussed on social equity and environmental protection, it emphasises on local and regional levels [23].

The RCM projections in Penang, Selangor and Johor were conducted for a reference period of the year 1980 to 2069 based on ECHAM4 A2 and ECHAM5 A1B scenarios and year 2010 to 2069 based on ECHAM4 B2 scenario. Two key climate parameters that were being projected namely temperature (in degrees Celsius) and precipitation (in millimetres). The minimum and maximum temperature analyses were conducted based on yearly average basis. The precipitation analysis was carried out by plotting the difference between the yearly average rainfall and the overall average rainfall throughout the reference period.

\section{Results and discussion}

All the three meteorological stations in the state of Penang, i.e. Perai, Bayan Lepas and Butterworth were used to represent Penang while all three meteorological stations in the state of Selangor, i.e. Subang, Petaling Jaya and KLIA Sepang were used to represent Selangor. The results for Johor were represented by all the four meteorological stations in the state of Johor, i.e. Batu Pahat, Kluang, Mersing and Senai. 


\subsection{Average minimum temperature analysis}

The average minimum temperature projections based on the three RCM scenarios for Penang, Selangor and Johor were plotted as shown in Fig. 2 - 4, respectively. All the three projected scenarios for the average minimum temperatures for Penang, Selangor and Johor showed a constant increasing trend. For Penang, the simulated average minimum temperature produced equations: $\mathrm{y}=0.0305 \mathrm{x}+28.445($ ECHAM4 A2), $\mathrm{y}=0.0302 \mathrm{x}+$ 28.389 (ECHAM4 B2) and $y=0.0345 x+21.653$ (ECHAM5 A1B) whereas for Selangor, the projected average minimum temperature yielded equations: $\mathrm{y}=0.0314 \mathrm{x}+21.918$ (ECHAM4 A2), $\mathrm{y}=0.0324 \mathrm{x}+21.803($ ECHAM4 B2) and $\mathrm{y}=0.0327 \mathrm{x}+21.347$ (ECHAM5 A1B). The simulated average minimum temperature for Johor formed equations: $\mathrm{y}=0.0307 \mathrm{x}+21.665($ ECHAM4 A2), $\mathrm{y}=0.0301 \mathrm{x}+21.609($ ECHAM4 B2) and $\mathrm{y}=$ $0.0322 \mathrm{x}+21.857$ (ECHAM5 A1B).

These equations predicted that there will be a rise in average minimum temperatures in 100 years' time for Penang: $3.1^{\circ} \mathrm{C}$ (ECHAM4 A2), $3.0^{\circ} \mathrm{C}$ (ECHAM4 B2) and $3.5^{\circ} \mathrm{C}$ (ECHAM5 A1B); whereas for Selangor: $3.1^{\circ} \mathrm{C}$ (ECHAM4 A2), $3.2^{\circ} \mathrm{C}$ (ECHAM4 B2) and $3.3^{\circ} \mathrm{C}$ (ECHAM5 A1B). Also, the equations suggested that there will be an increase in average minimum temperatures in 100 years' time for Johor by $3.1^{\circ} \mathrm{C}, 3.0^{\circ} \mathrm{C}$ and $3.2^{\circ} \mathrm{C}$ based on ECHAM4 A2, B2 and ECHAM5 A1B scenarios, respectively.

Generally, higher average minimum temperatures were observed in the results simulated based on ECHAM4 A2 and B2 scenarios for Penang and Selangor as compared to those simulated based on ECHAM5 A1B scenario. However, this is not the case for Johor whereby the average minimum temperatures projected based on ECHAM5 A1B scenario were much higher than the other two scenarios throughout the same years comparatively. It is found that the average minimum temperatures projected based on ECHAM4 A2 and B2 scenarios for Penang are exceptionally high which is probably due to the location of it being surrounded by the sea as compared to the mainland [24].

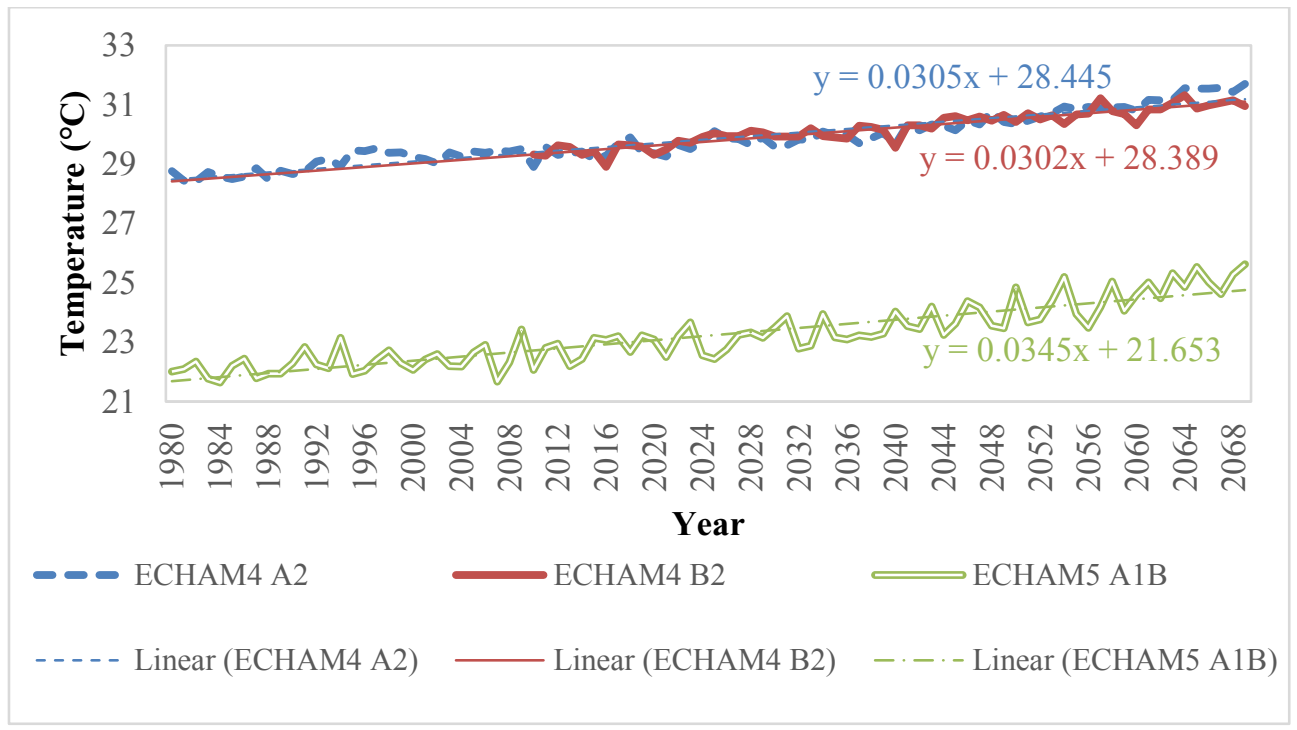

Fig. 2. Comparison of ECHAM4 A2 and ECHAM5 A1B scenarios (1980-2069) and ECHAM4 B2 scenario (2010-2069) average minimum temperature projections for Penang 


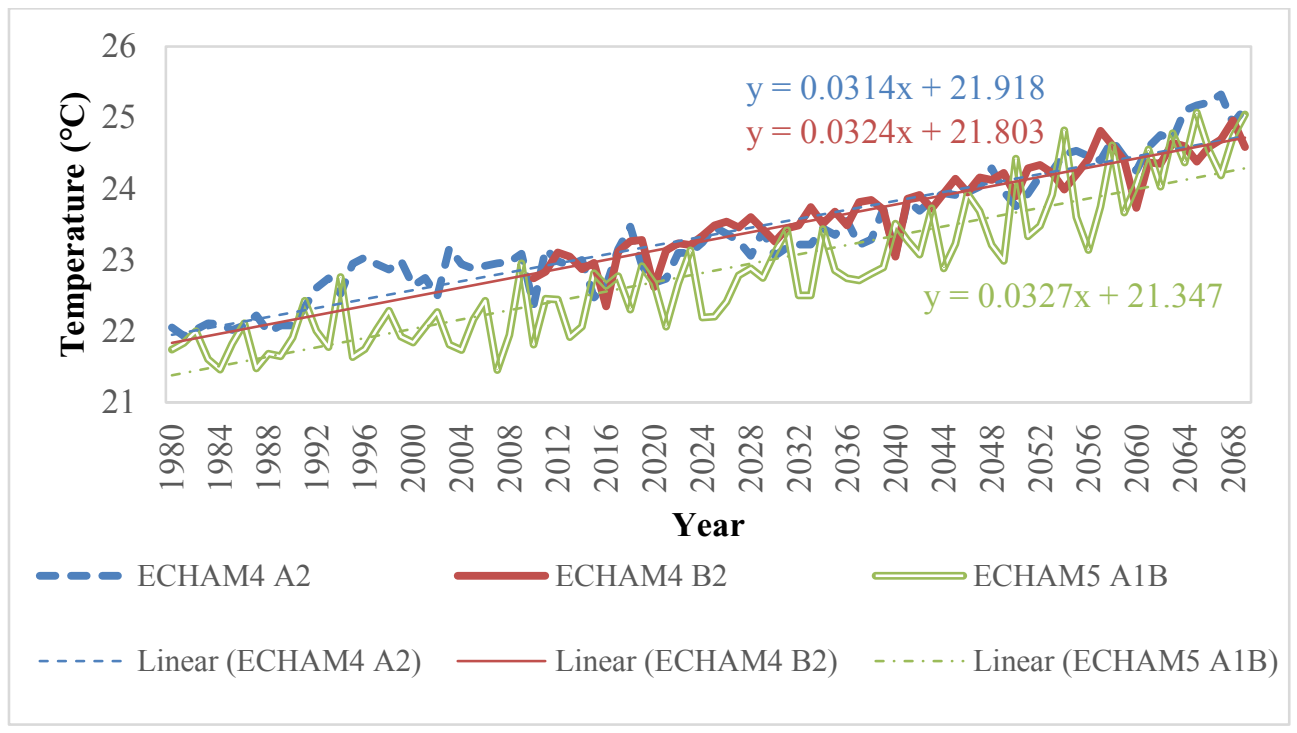

Fig. 3. Comparison of ECHAM4 A2 and ECHAM5 A1B scenarios (1980-2069) and ECHAM4 B2 scenario (2010-2069) average minimum temperature projections for Selangor

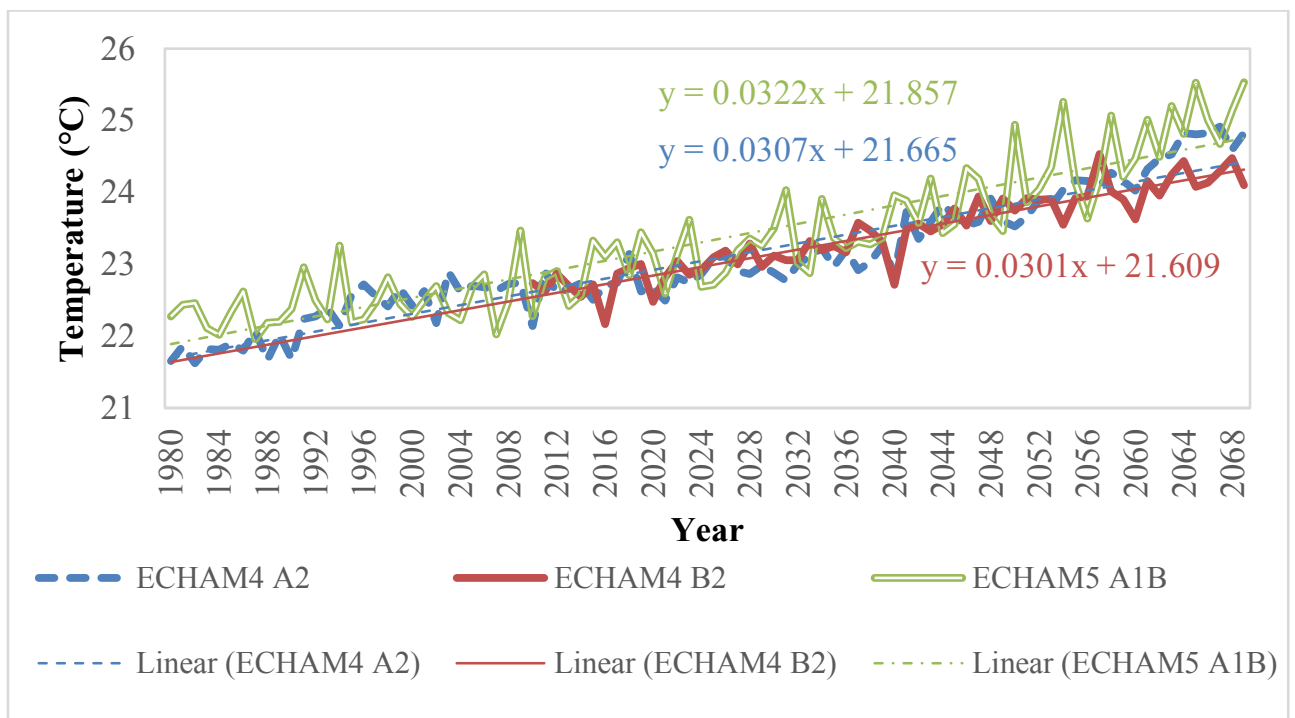

Fig. 4. Comparison of ECHAM4 A2 and ECHAM5 A1B scenarios (1980-2069) and ECHAM4 B2 scenario (2010-2069) average minimum temperature projections for Johor

\subsection{Average maximum temperature analysis}

The average maximum temperature projections based on the three RCM scenarios for Penang, Selangor and Johor were plotted as shown in Fig. 5-7, respectively. Similar to the average minimum temperature projections, all the three projected scenarios for the average 
maximum temperatures for Penang, Selangor and Johor also showed a steady increasing trend. An outlier is observed in the average maximum temperature projections for all the three states in the year 2037 based on ECHAM5 A1B scenario, which could have been caused by an experimental error in the RCM. For Penang, the simulated average maximum temperature produced equations: $\mathrm{y}=0.0251 \mathrm{x}+33.777($ ECHAM4 A2), $\mathrm{y}=0.0265 \mathrm{x}+$ 33.632 (ECHAM4 B2) and $y=0.0269 x+31.195$ (ECHAM5 A1B) whereas for Selangor, the projected average maximum temperature yielded equations: $\mathrm{y}=0.0219 \mathrm{x}+32.497$ (ECHAM4 A2), $\mathrm{y}=0.0283 \mathrm{x}+32.132($ ECHAM4 B2) and $\mathrm{y}=0.0311 \mathrm{x}+29.969$ (ECHAM5 A1B). The simulated average maximum temperature for Johor formed equations: $\mathrm{y}=0.0248 \mathrm{x}+29.903($ ECHAM4 A2), $\mathrm{y}=0.0273 \mathrm{x}+29.724$ (ECHAM4 B2) and $\mathrm{y}=0.0288 \mathrm{x}+30.013$ (ECHAM5 A1B).

These equations predicted that there will be a rise in average maximum temperatures in 100 years' time for Penang: $2.5^{\circ} \mathrm{C}$ (ECHAM4 A2), $2.7^{\circ} \mathrm{C}$ (ECHAM4 B2) and $2.7^{\circ} \mathrm{C}$ (ECHAM5 A1B); and for Selangor: $2.2^{\circ} \mathrm{C}$ (ECHAM4 A2), $2.8^{\circ} \mathrm{C}$ (ECHAM4 B2) and $3.1^{\circ} \mathrm{C}$ (ECHAM5 A1B). Also, the equations indicated that there will be an increase in average maximum temperatures in 100 years' time for Johor by $2.5^{\circ} \mathrm{C}, 2.7^{\circ} \mathrm{C}$ and $2.9^{\circ} \mathrm{C}$ based on ECHAM4 A2, B2 and ECHAM5 A1B scenarios, respectively.

Basically, higher average maximum temperatures were observed in the results simulated based on ECHAM4 A2 and B2 scenarios for Penang and Selangor as compared to those simulated based on ECHAM5 A1B scenario. But, this is not the case for Johor whereby the average maximum temperatures projected based on all the three scenarios were about the same throughout the same years comparatively. Similar to the average minimum temperatures projected based on ECHAM4 A2 and B2 scenarios for Penang, the average maximum temperatures projected based on these two scenarios for this state were also found to be much higher due to the coastal effect as compared to the mainland [24].

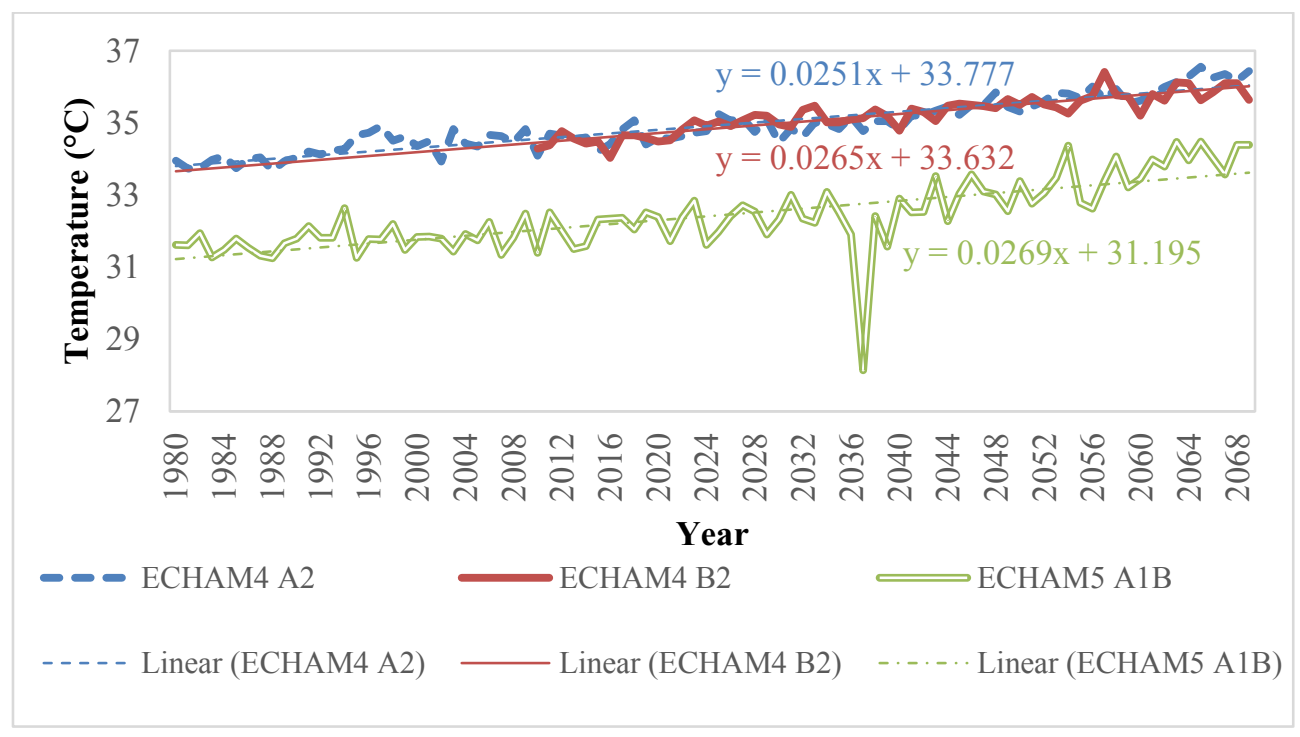

Fig. 5. Comparison of ECHAM4 A2 and ECHAM5 A1B scenarios (1980-2069) and ECHAM4 B2 scenario (2010-2069) average maximum temperature projections for Penang 


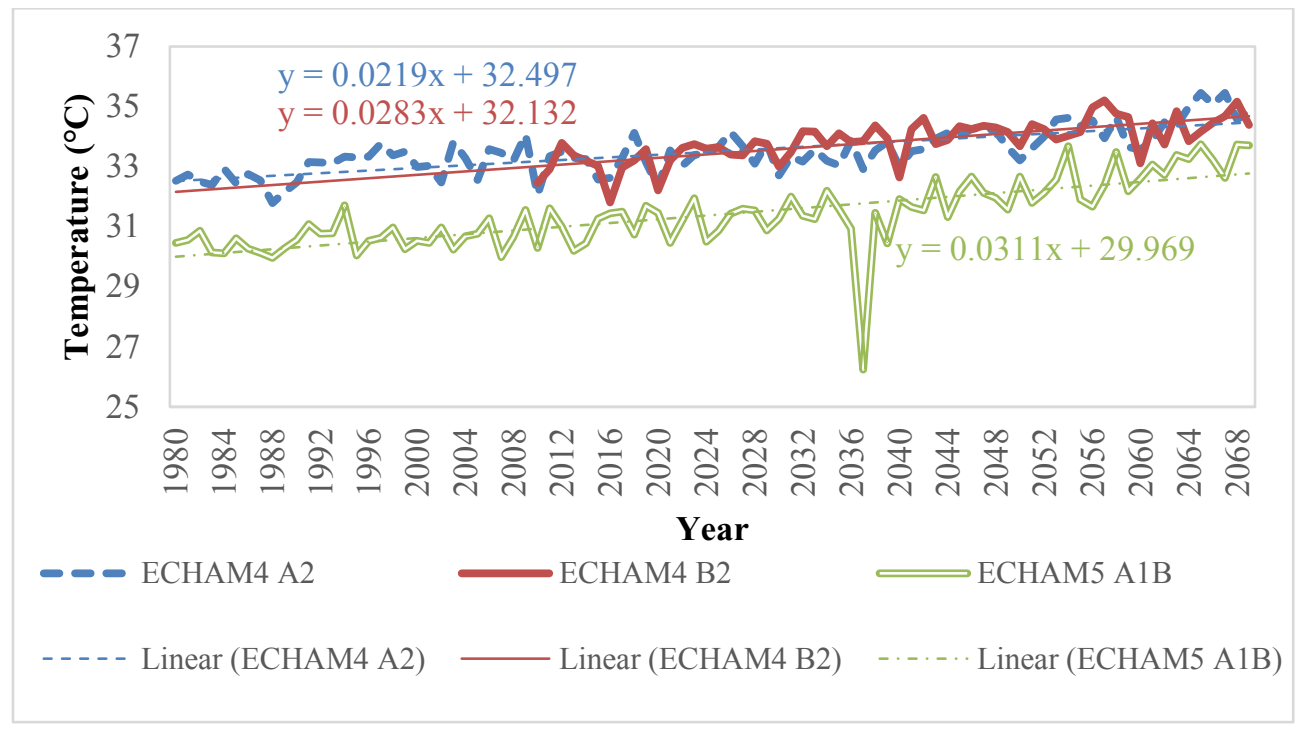

Fig. 6. Comparison of ECHAM4 A2 and ECHAM5 A1B scenarios (1980-2069) and ECHAM4 B2 scenario (2010-2069) average maximum temperature projections for Selangor

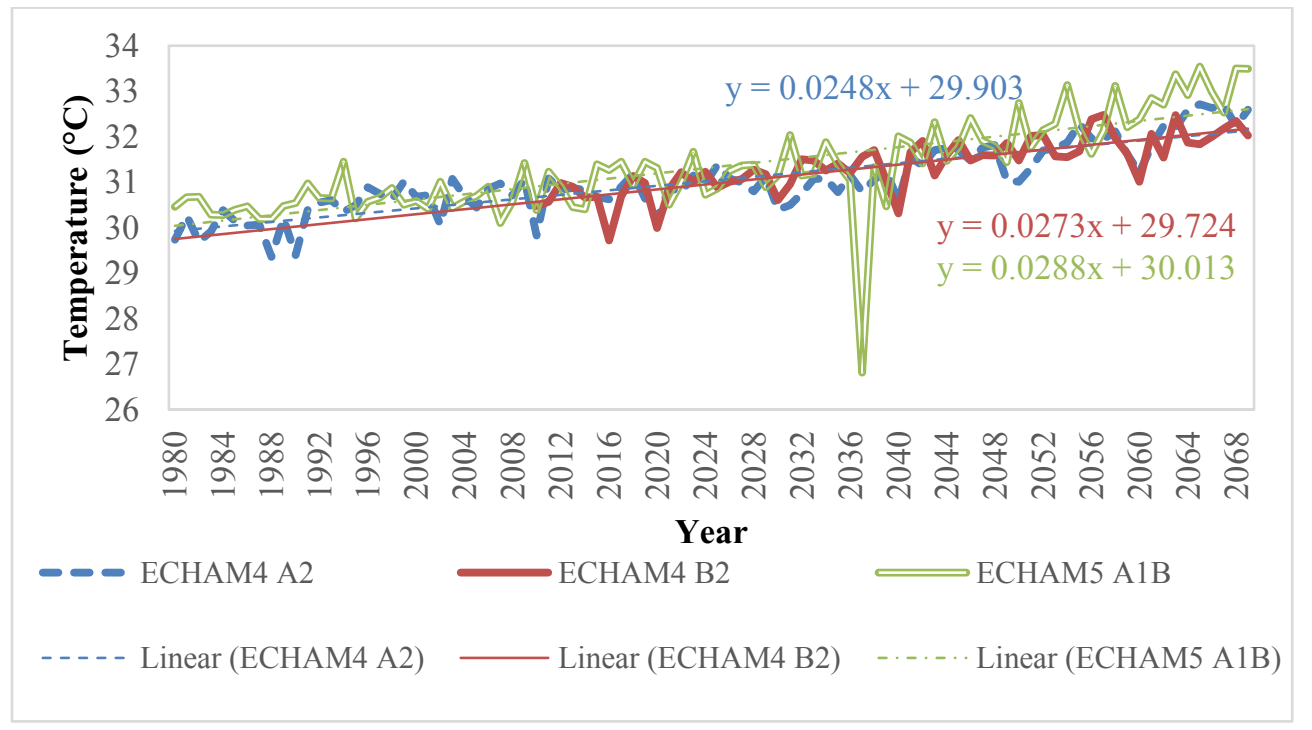

Fig. 7. Comparison of ECHAM4 A2 and ECHAM5 A1B scenarios (1980-2069) and ECHAM4 B2 scenario (2010-2069) average maximum temperature projections for Johor

\subsection{Average precipitation analysis}

The average precipitation projections based on the three RCM scenarios for Penang, Selangor and Johor were plotted as shown in Fig. 8-10, respectively. 


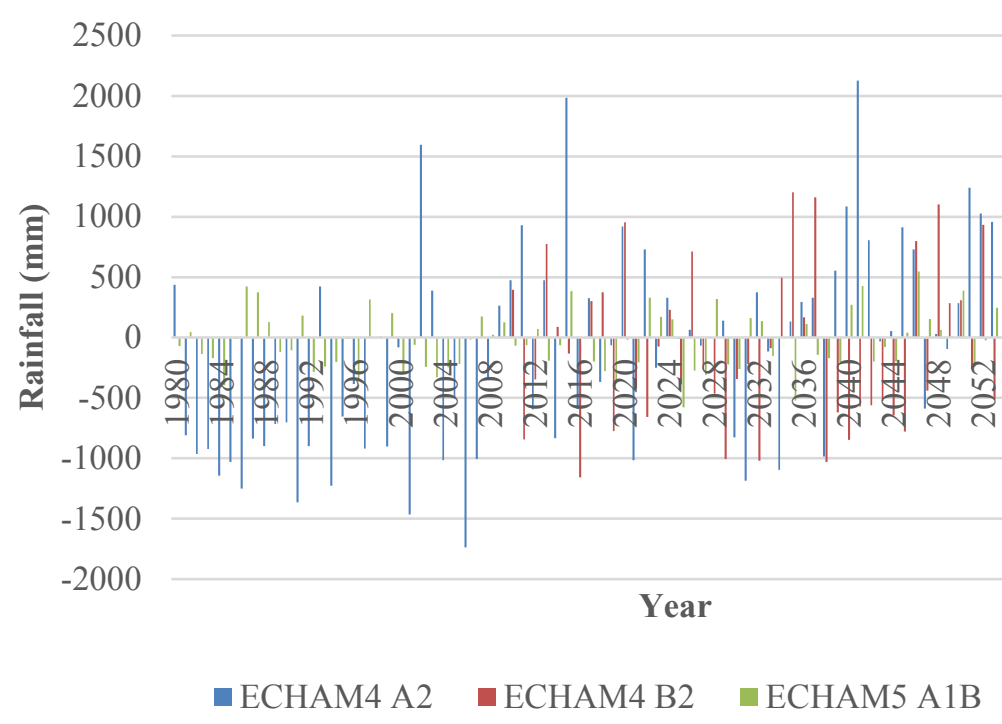

Fig. 8. Comparison of ECHAM4 A2 and ECHAM5 A1B scenarios (1980-2069) and ECHAM4 B2 scenario (2010-2069) average precipitation projections for Penang

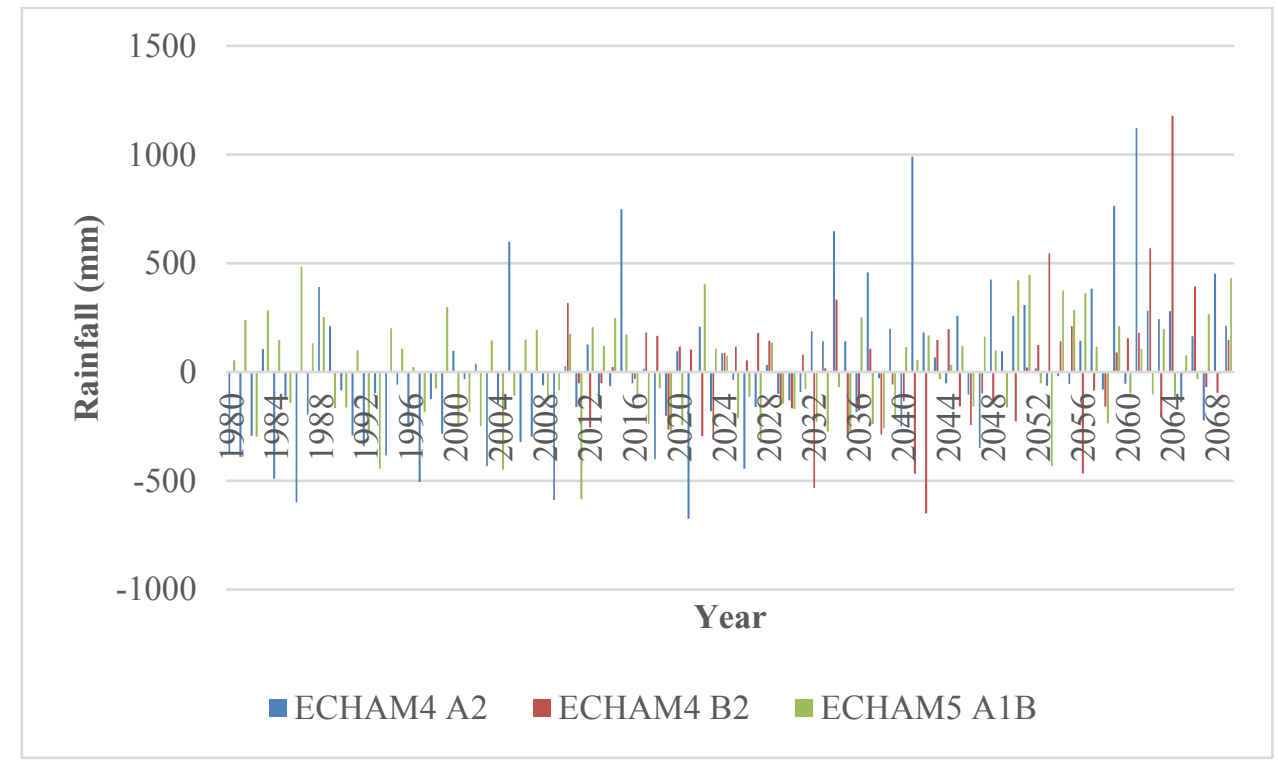

Fig. 9. Comparison of ECHAM4 A2 and ECHAM5 A1B scenarios (1980-2069) and ECHAM4 B2 scenario (2010-2069) average precipitation projections for Selangor 


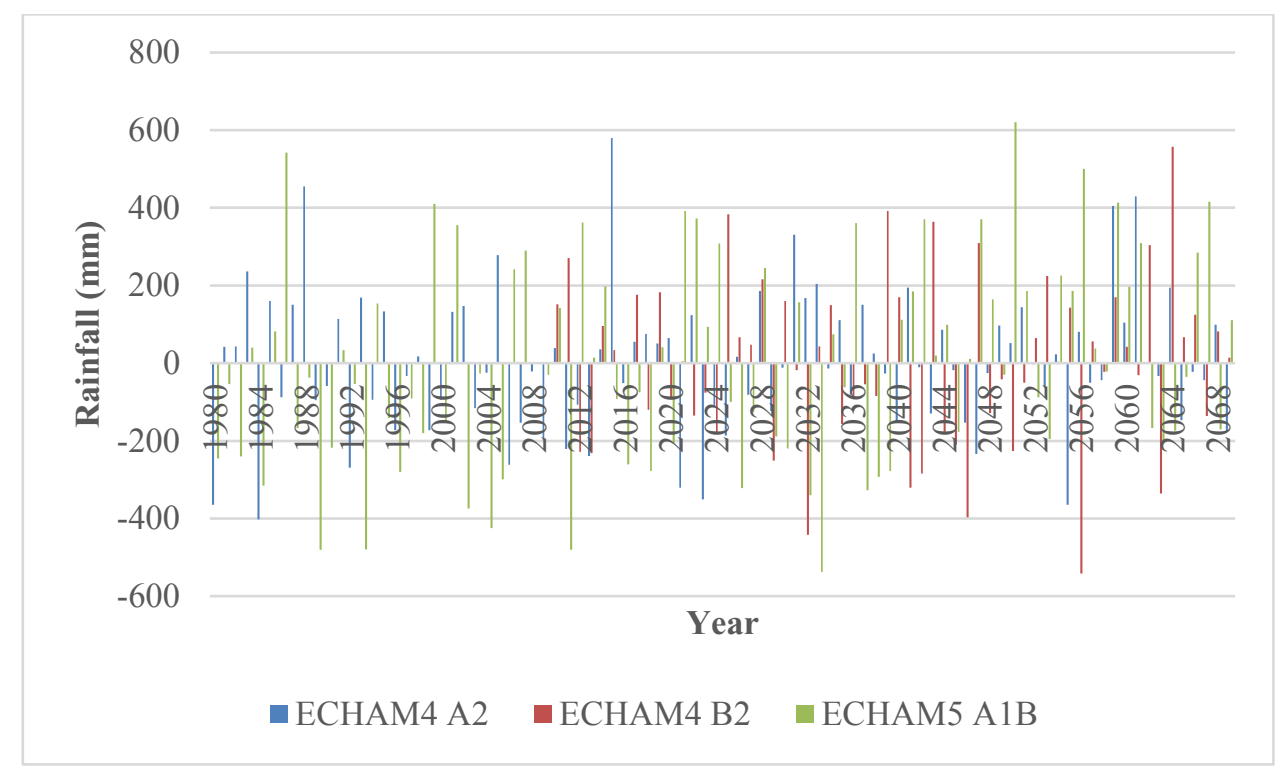

Fig. 10. Comparison of ECHAM4 A2 and ECHAM5 A1B scenarios (1980-2069) and ECHAM4 B2 scenario (2010-2069) average precipitation projections for Johor

As shown in the comparison charts (Fig. 8 - 10), the average precipitation simulated based on all the three scenarios for Penang and Selangor were observed to show an increasing trend. These results pointed out there is a steady increase of rainfall from the beginning till the end of the reference period. However, this trend is not seen in Johor whereby the average precipitation projected based on all the three scenarios were more stable throughout the reference period. Also, it is obvious that the overall average precipitation projected based on all the three scenarios for Penang are higher than Selangor and Johor which could also be attributed by the location of it being a coastal area as compared to the mainland [24].

\section{Conclusions}

The projections based on ECHAM4 A2 and B2 scenarios (for the years 1980 to 2069) exhibited higher temperatures for Penang and Selangor as compared to ECHAM5 A1B (for the years 2010 to 2069). However, an opposite trend was observed for Johor. The average precipitation simulated based on all the three scenarios for Penang and Selangor were observed to show an increasing trend but it is not the same for Johor. Penang showed higher temperatures in most cases and higher precipitation which are probably due to the fact that it is a coastal area which is more affected by the monsoon in this region.

We would like to express our gratitude to UTAR for funding this project under UTAR Research Fund and Southeast Asia START (System for Analysis, Research and Training) Regional Centre, Chulalongkorn University, Thailand for providing the RCM data.

\section{References}

1. IPCC, Summary for Policymakers. In: Climate Change 2007: The Physical Science Basis. Contribution of Working Group I to the Fourth Assessment Report of the 
Intergovernmental Panel on Climate Change (Cambridge University Press, Cambridge, 2007)

2. H. J. Fowler, S. Blenkinsop, C. Tebaldi, Int. J. Climatol., 27(12), 1547 (2007)

3. G. Bürger, T. Q. Murdock, A. T. Werner, S. R. Sobie, A. J. Cannon, J. Clim., 25(12), $4366(2012)$

4. C. F. Fung, A. Lopez, M. New (Eds.) Modelling the impact of climate change on water resources. (Blackwell Publication Limited, West Sussex, 2011)

5. W. P. Anderson, R. E. Storniolo, J. S., J. Hydrol., 409(1), 525 (2011)

6. S. Bergström, B. Carlsson, M. Gardelin, G. Lindström, A. Pettersson, M. Rummukainen, Clim. Res., 16(2), 101 (2001)

7. R. L. Wilby, S. P. Charles, E. Zorita, B. Timbal, P. Whetton, L. O. Mearns, IPCC TGCIA, 27 (2004)

8. J. Shi, Q. Yan, H. Wang, D. Jiang, J. Min, Y. Jiang, Palaeogeogr. Palaeoclimatol. Palaeoecol., 480, 70 (2017)

9. J. R. Brown, A. F. Moise, R. A. Colman, Geophys. Res. Lett., 44(11), 5683 (2017)

10. H. Annamalai, B. Taguchi, K. R. Sperber, J. P. McCreary, M. Ravichandran, A. Cherchi, G. Martin, A. Moise, Clivar Exch., 66, 19 (2015)

11. A. Chevuturi, N. P. Klingaman, A. G. Turner, S. Hannah, Earth's Future, 6(3), 339 (2018)

12. A. R. As-syakur, T. Osawa, F. Miura, I. W. Nuarsa, N. W. Ekayanti, I. G. B. S. Dharma, ..., T. Tanaka, Dyn. Atmos. Oceans, 75, 58 (2016)

13. L. Juneng, F. T. Tangang, Atmos. Sci. Lett., 11(3), 199 (2010)

14. Y. Y. Loo, L. Billa, A. Singh, Geosci. Front., 6(6), 817 (2015)

15. T. Suepa, J. Qi, S. Lawawirojwong, J. P. Messina, Environ. Res., 147, 621 (2016)

16. M. Xu, C. P. Chang, C. Fu, Y. Qi, A. Robock, D. Robinson, H. M. Zhang, J. Geophys. Res. Atmos., 111, D24 (2006)

17. R. Yu, T. Zhou, J. Clim., 20(21), 5344 (2007)

18. The Office of Chief Statistician Malaysia, Table 30: GDP by State, 2010-2016 at Current Prices - RM Million (in Malay and English), 17 (DOS, Putrajaya, 2017)

19. M. E. Diimenil, M. Giorgetta, U. Schlese, U. Schullzweida, Max Planck Inst. Meteorol., 218, 90 (1996)

20. E. Roeckner, G. Bäuml, L. Bonventura, R. Brokopf, M. Esch, M. Giorgetta, ..., A. Rhodin, Max Planck Inst. Meteorol., 349 (2003)

21. R. G. Jones, M. Noguer, D. C. Hassell, D. Hudson, S. S. Wilson, G. J. Jenkins, J. F. B. Mitchell, Generating high resolution climate change scenarios using PRECIS (Met Office Hadley Centre, Exeter, 2004)

22. IPCC, Special Report on Emission Scenarios (SRES): Special Report of Working Group III of IPCC (Cambridge University Press, Cambridge, 2000)

23. N. Nakicenovic, , J. Alcamo, A. Grubler, K. Riahi, R. A. Roehrl, H. H. Rogner, N. Victor, Special report on emissions scenarios (SRES), a special report of Working Group III of the intergovernmental panel on climate change (Cambridge University Press, Cambridge, 2000)

24. M. Allaby, How the Weather Works (Reader's Digest Association Inc., New York, 1995) 